\title{
8. CONCLUSION
}

You have now witnessed a 'thumb-nail sketch' of the theatre team at work. Each one doing their own task for better patient care and safety. You will have the opportunity of witnessing doctors working for prolonged periods and often under stress. At other times you will hear them discuss their ideas on politics or whatever. Hence theatres can be hotbeds of personality clashes! Consider this when you are next in an annoying situation. Concern yourself only with good technique for the patient's safety, keep the surgeon and anaesthetist happy so they work well for the patient, and constantly remember you are the patient's representative to anticipate and care for his/her needs.

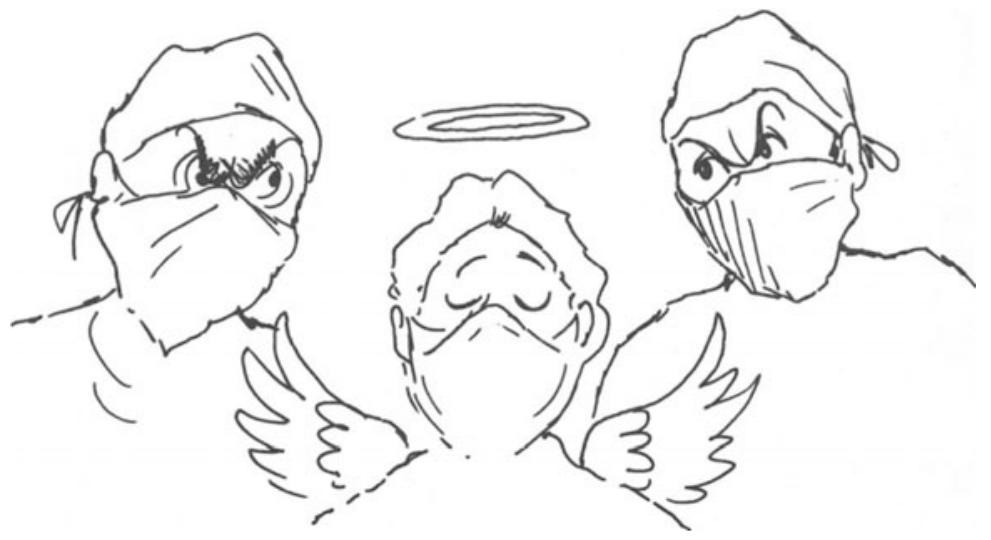

